\title{
Xeroderma pigmentosum-Cockayne syndrome complex
}

INSERM

\section{Source}

INSERM. (1999). Orphanet: an online rare disease and orphan drug data base. Xeroderma pigmentosum-Cockayne syndrome complex. ORPHA:220295

Xeroderma pigmentosum/Cockayne syndrome complex (XP/CS complex) is

characterized by the cutaneous features of xeroderma pigmentosum (XP) (see this term) together with the systemic and neurological features of Cockayne syndrome (CS; see this term). 